
\title{
is Research Square \\ Influence of Depression on Physical and Mental Health in Patients with Angina
}

Dr. Raed Abdullah Alharbi ( $\sim$ r.abdullah@mu.edu.sa )

Majmaah University

Research article

Keywords: Depression, Angina, Physical Health, Mental Health, Health Informatics, BRFSS

Posted Date: August 21st, 2020

DOl: https://doi.org/10.21203/rs.3.rs-59373/v1

License: (c) (i) This work is licensed under a Creative Commons Attribution 4.0 International License.

Read Full License 


\section{Abstract}

Purpose: Angina is well known as chest pain caused by insufficient flow of oxygen-rich blood to the cardiac muscle. Although there are several studies showing an association between depression and angina, none of these studies investigated the influence of depression on the physical and mental health of adult patients with angina, which is the overall goal of this study.

Methods: This study used a publicly open data source from the Behavioral Risk Factor Surveillance System (BRFSS), 2017, in the United States. The BRFSS questionnaire relating to health, behaviors, and social life was administered to the United States residents through a telephone interview. There were 450,013 participants in this survey. Different statistical methods, including descriptive, inferential, and predictive methods, were conducted through the Statistical Analysis System (version 9.4) to accomplish the goal of this study.

Results: Of the 450,013 participants in the BRFSS 2017, 25,389 were adult patients diagnosed with angina. Of these, 22,875 have depression. This study showed that depression had a statistically significant influence on physical and mental health in adult patients with angina.

Conclusion: Depression has a significant influence on physical and mental health of adult patients with angina. Depression increased the physical health problems by $61.95 \%$ and mental health problems by $33.15 \%$ in adult patients with angina.

\section{Introduction}

Angina is well known as chest pain caused by insufficient flow of oxygen-rich blood to the cardiac muscle $[1,2]$. In some cases, this pain may spread to the back, arms, shoulders, or neck [1]. It is symptom of cardiac problems, commonly coronary heart disease (CHD) [3,4].

There are four common types of angina: stable, unstable, microvascular, and variant angina $[1,3]$. Stable angina always follows a specific pattern, while unstable angina does not follow a specific pattern [4]. Microvascular angina is a common type of angina, while variant angina is a rare type [3].

Angina may result mainly from ischemic heart disease or spasm of the coronary arteries. However, there are several risk factors, such as smoking, hypertension, metabolic syndrome, unhealthy cholesterol levels, diabetes, obesity, and inactivity $[1,4]$.

According to the American Heart Association report in 2016, 15.5 million American individuals had CHD in 2012 , which is the main cause of angina, and $8.2 \%$ of these patients had angina. Researchers expected that by $2030, \mathrm{CHD}$ prevalence would increase by $18 \%$ from 2013 [5].

Although depression is another health condition, the American Heart Association reported that depression worsens the condition of the heart especially in patients with CHD [6]. To better understand the effects of depression on the heart, basic knowledge of depression is essential. 
Depression is a mood disorder that affects the way of thinking and behavior and leads to constant feelings of sadness $[7,8]$. Moreover, it can also cause physical and mental problems, leading to a decrease in the activity and functioning ability of the patient diagnosed with this disorder $[7,8]$.

Feelings of sadness, grief, and bereavement may develop in an individual's life. However, it is totally different in depression because these feelings are constant [8]. Fortunately, depression can be treated, but it may require a long time $[7,8]$.

Thus, according to the American Heart Association, depression affects the heart in two possible ways: (1) constant feelings of stress, sadness, and anxiety usually lead patients to unhealthy choices, especially with regard to food or exercise, and (2) depression can lead the body to produce certain hormones adversely affecting cholesterol levels and blood pressure [6].

According to the National Institute of Mental Health, in 2016, there were approximately 16.2 million patients with depression in the United States. ${ }^{9}$ However, in 2017, the number of patients increased to approximately 17.3 million [9].

Several studies showed that there is a relationship between depression and angina with respect to the effects in a patient's life. According to Szpakowski et al., depression is commonly associated with angina, leading to high morbidity and mortality rates in patients with this disorder [10].

A study by Thombs et al. on patients with acute myocardial infarction (AMI) showed that survivors of AMI have constant depression [11]. Moreover, according to Kaptein et al., symptoms of depression after myocardial infarction are considered important risk factors of developing other cardiac conditions [12].

Although there are several studies showing the relationship among depression, angina, and patients' quality of life, there is no specific study that showed the effect of the association between these two conditions on physical and mental health of patients. Therefore, this study aimed to investigate the influence of depression on the physical and mental health of adult patients with angina.

\section{Patients And Methods:}

This study used a publicly open available data source from the 2017 Behavioral Risk Factor Surveillance System (BRFSS) from the Centers for Disease Control and Prevention (CDC) to investigate the effect of depression on physical and mental health of adult patients with angina. CDC stated that BRFSS data is released for public use [13]. Also, the author of this manuscript has bioethics certificate No. 10014263.

The CDC established the BRFSS to be the first national Faculty of Health questionnaire collected from United States residents by telephone interview in relation to their health and different types of diseases, as well as their behaviors and social life [13]. The population in this study included adult patients with angina (18-65 years) and those of both genders and different races from all states of the United States [13]. 
The variables of this study were based on two questions for the predictor variables and two questions for the indicator variables. The predictor variable questions include the presence of angina (CVDCRHD4) and presence of depression (ADDEPEV2). In contrast, the indicator variable questions include self-assessment of the presence of physical health problems (PHYSHLTH) and self-assessment of the presence of mental health problems (MENTHLTH).

This study used the descriptive, inferential, and predictive analysis methods through the Statistical Analysis System (SAS version 9.4) to determine the effect of depression on the physical and mental health of adult patients with angina.

After cleaning the large data, the first step was to apply certain methods of frequency distributions to describe the study variables. Then, the second step of the investigation was to conduct certain inferential analysis methods, such as the chi-square test, to evaluate the association between these variables with a significance level of P-value $\leq 0.05$. The final step was to confirm the relationship among these variables and calculate the percentage differences using a predictive analysis method, such as logistic regression.

\section{Results:}

There were 450,013 participants in the BRFSS 2017. Of these, 25,389 were adult patients diagnosed with angina. There were 14,915 men and 10,259 women. Of these, 89,209 were diagnosed with depression. Of the adult patients diagnosed with depression, 22,875 had angina (Figure 1).

Figure 1. Distribution of adult patients with angina.

Of the adult patients with angina, 23,284 who did not have depression and 20,816 who had depression had physical health problems (Table 1). Moreover, 20,083 who did not have depression and 18,567 who had depression had mental health problems (Table 1).

Table 1. Distribution of adult patients with angina by physical and mental health problems

\begin{tabular}{|llll|}
\hline \multicolumn{2}{|l|}{ Distribution of adult patients with angina } \\
\hline Variables & & Angina without depression & Angina with depression \\
\hline Physical health problems & Male & 13,301 & 12,025 \\
\cline { 2 - 4 } & Female & 9,983 & 8,791 \\
\cline { 2 - 4 } & Total & 23,284 & 20,816 \\
\hline Mental health problems & Male & 11,351 & 10,254 \\
\cline { 2 - 4 } & Female & 8,732 & 8,313 \\
\cline { 2 - 4 } & Total & 20,083 & 18,567 \\
\hline
\end{tabular}


The chi-square test was used to examine the association between the study variables, including angina and depression as predictor variables and physical and mental health problems as indicator variables (Table 2).

Table 2. P-values in the chi-square test that was used to examine the association between predictor and indicator variables

\begin{tabular}{|c|c|c|c|}
\hline \multicolumn{4}{|c|}{ P-values in the chi-square test } \\
\hline \multicolumn{2}{|c|}{ Indicator variables of HRQoL } & \multicolumn{2}{|c|}{ Predictor variables } \\
\hline & & Angina & Angina and depression \\
\hline \multirow[t]{2}{*}{ Physical health problems } & Male & $<0.0001$ & $<0.0001$ \\
\hline & Female & $<0.0001$ & $<0.0001$ \\
\hline \multirow[t]{2}{*}{ Mental health problems } & Male & $<0.0001$ & $<0.0001$ \\
\hline & Female & $<0.0001$ & $<0.0001$ \\
\hline
\end{tabular}

Logistic regression was applied to confirm the relationship between the study variables, including angina and depression as predictor variables and physical and mental health problems as indicator variables (Table 3).

Table 3. P-value and odds ratio of logistic regression to confirm the relationship between predictor and indicator variables and calculate the percentage differences

\begin{tabular}{|lllll|}
\hline \multicolumn{3}{|l|}{ P-values and odds ratio of logistic regression } & & \\
\hline Indicator variables & \multicolumn{2}{l|}{ Predictor variable } & & \\
\cline { 2 - 5 } & \multicolumn{2}{l}{ Angina } & & Angina and depression \\
\cline { 2 - 5 } & $\mathrm{Pr}>$ chi-Sq & $\mathrm{OR}$ & $\mathrm{Pr}>$ chi-Sq & OR \\
\hline Physical health problems & $<0.0001$ & 0.732 & $<0.0001$ & 1.389 \\
\hline Mental health problems & $<0.0001$ & 0.853 & $<0.0001$ & 1.192 \\
\hline
\end{tabular}

To calculate the percentage differences of the effect of angina alone and angina with depression on physical and mental health problems, the odds ratio (OR) must be obtained by logistic regression (Table $3)$.

\section{Discussion:}

One of the best methods to assess a specific population is to measure health using reliable and sensitive scales to obtain significant and interpretable results for that specific population. Since several studies 
showed that depression has the ability to worsen angina as a health condition and none of these studies investigated the influence of depression on physical and mental health in adult patients with angina, this study aimed to investigate that influence by measuring physical and mental health problems in adult patients with angina.

This study used data from the BRFSS 2017 , which had 450,013 participants, to confirm the influence of depression on physical and mental health of adult patients with angina. This study applied different statistical methods, including descriptive, inferential, and predictive methods, through the Statistical Analysis System (SAS version 9.4).

In the descriptive analysis, of the 450,013 participants in the BRFSS 2017, 25,389 were adult patients diagnosed with angina. There were 14,915 men and 10,259 women. Of these, 89,209 were diagnosed with depression. Of the adult patients with depression, 22,875 had angina (Figure 1). Moreover, of the adult patients with angina who did not have depression, 23,284 had physical health problems and 20,083 had mental health problems. In contrast, of the adult patients with angina who had depression, 20,816 had physical health problems and 18,567 had mental health problems (Table 1).

In the inferential analysis, the chi-square test was used to examine the association between study variables, including angina and depression as predictor variables and physical and mental health problems as indicator variables. By choosing a significance level of P-value $\leq 0.05$, all results of the inferential analysis showed P-values $<0.0001$, indicating that there are significant associations among angina, depression, and physical and mental health problems (Table 2).

In the predictive analysis, logistic regression was applied to confirm the relationship between study variables, including angina and depression as predictor variables and physical and mental health problems as indicator variables. All results of the predictive analysis showed that the relationship among angina, depression, and physical and mental health problems is significant with $\mathrm{Pr}>$ chi-Sq. $<0.0001$ (Table 3).

Furthermore, the OR were obtained by logistic regression to calculate the percentage differences of the effect of angina alone and angina with depression on physical and mental health problems (Table 3).

Percentage differences of the influence can be calculated using the following equation: [14] Percentage differences $=(\mathrm{VI}-\mathrm{V} 2) /((\mathrm{V} 1+\mathrm{V} 2) / 2) * 100$

where

V1 $=$ number of exposed cases

V2 = number of non-exposed cases

The OR of physical health problems in adult patients with angina who did not have depression is 0.732 , while that in adult patients with angina who had depression is 1.389 (Table 3 ). This indicates that adult 
patients with angina who had depression have $61.95 \%$ more physical health problems than adult patients with angina who did not have depression.

The OR of mental health problems in adult patients with angina who did not have depression is 0.853 , while that in adult patients with angina who had depression is 1.192 (table 3). This indicates that adult patients with angina who had depression have $33.15 \%$ more mental health problems than adult patients with angina who did not have depression.

\section{Conclusion:}

This study aimed to investigate the influence of depression on physical and mental health of adult patients with angina. Data were obtained from the BRFSS 2017 of the CDC. The results of this study were based on 25,389 adult patients with angina, and 22,875 of these patients had depression. This study used different statistical methods, including descriptive, inferential, and predictive methods, through the Statistical Analysis System (SAS version 9.4). The study showed that depression can increase physical health problems by $61.95 \%$ and mental health problems by $33.15 \%$ in adult patients with angina.

Therefore, based on these findings, depression has a great influence on the physical and mental health of adult patients with angina. However, although this study showed the influence of depression on physical and mental health in adult patients with angina in both genders, a limitation of this study is that it remains unknown whether depression affects the health of men more than that in women

\section{Declarations}

\section{Acknowledgement:}

The author would like to thank Deanship of Scientific Research at Majmaah University, Al Majmaah, 11952, Saudi Arabia for supporting this work under the Project Number X-XXXX-XX

\section{Authors' contributions:}

The work was done by only one author.

\section{Funding:}

There was no source of funding.

\section{Availability of data and materials:}

All data are available on reasonable request.

\section{Ethics approval and consent to participate:}

Not applicable. The data is publicly available, and no approval is required. 


\section{Consent for publication:}

Not applicable. The paper does not involve the use of any individual person's data.

\section{Competing interests:}

The author declares that there are no competing interests.

\section{References}

[1] American Heart Association (AHA). a2019. Angina (Chest Pain). Retrieved on 13-08-2019 from www.heart.org/en/health-topics/heart-attack/angina-chest-pain

[2] National Heart, Lung, and Blood Institute (NHLBI). 2019. Angina. Retrieved on 14-08-2019 from www.nhlbi.nih.gov/health-topics/angina

[3] Mann D, Zipes D, Libby P, Bonow R. 2014. Braunwald's heart disease: a textbook of cardiovascular medicine. 10th ed. Saunders. Single volume. 9780323294294.

[4] Goldman L, Schafer A. Goldman-Cecil medicine. 2016. 25th ed. Elsevier. 2-Volume Set. ISBN; 9781455750177.

[5] Mozaffarian D, Benjamin EJ, Go AS, Arnett DK, Blaha MJ, Cushman M, Das SR, de Ferranti S, Després JP, Fullerton HJ, Howard VJ, Huffman MD, Isasi CR, Jiménez MC, Judd SE, Kissela BM, Lichtman JH, Lisabeth LD, Liu S, Mackey RH, Magid DJ, McGuire DK, Mohler ER 3rd, Moy CS, Muntner P, Mussolino ME, Nasir K, Neumar RW, Nichol G, Palaniappan L, Pandey DK, Reeves MJ, Rodriguez CJ, Rosamond W, Sorlie PD, Stein J, Towfighi A, Turan TN, Virani SS, Woo D, Yeh RW, Turner MB. 2016. Heart disease and stroke statistics. Update: a report from the American Heart Association. Circulation 2016; 133: e38-e360. doi: 10.1161/CIR.0000000000000350.

[6] American Heart Association (AHA). b2019. How does depression affect the heart? Retrieved on 22-082019 from https://www.heart.org/en/healthy-living/healthy-lifestyle/mental-health-and-wellbeing/howdoes-depression-affect-the-heart

[7] American Psychiatric Association (APA). 2013. Diagnostic and Statistical Manual of Mental Disorders (DSM-5). 5th ed.

[8] American Psychiatric Association (APA). 2019. What Is depression? Retrieved on 18-08-2019 from https://www.psychiatry.org/patients-families/depression/what-is-depression

[9] National Institute of Mental Health (NIMH). 2019. Major depression Retrieved on 13-07- 2019 from www.nimh.nih.gov/health/statistics/prevalence/major-depression-among-adults.shtml 
[10] Szpakowski N, Bennell MC, Qiu F, Ko DT, Tu JV, Kurdyak P, Wijeysundera HC. 2016. Clinical impact of subsequent depression in patients with a new diagnosis of stable angina. A population-based study. Circulation 2016. doi:10.1161.

[11] Thombs BD, Bass EB, Ford DE, Stewart KJ, Tsilidis KK, Patel U, Fauerbach JA, Bush DE, Ziegelstein RC. Prevalence of depression in survivors of acute myocardial infarction. J Gen Intern Med 2006; 21: 3038.

[12] Kaptein Kl, de Jonge P, van den Brink RH, Korf J. 2006. Course of depressive symptoms after myocardial infarction and cardiac prognosis: a latent class analysis. Psychosom; 68: 662-668. doi: 10.1161/CIRCOUTCOMES.116.002904.

[13] Behavioral Risk Factor Surveillance System (BRFSS). 2018. 2017 BRFSS Survey Data and Documentation. Retrieved on 22-06-2019 from https://www.cdc.gov/brfss/annual_data/annual_2017.html

[14] Clemson University. Physics Tutorial: \% Error \& \% Difference. 2006. Retrieved on 03-09-2019 from http://www.clemson.edu/ces/phoenix/tutorials/error/

\section{Figures}

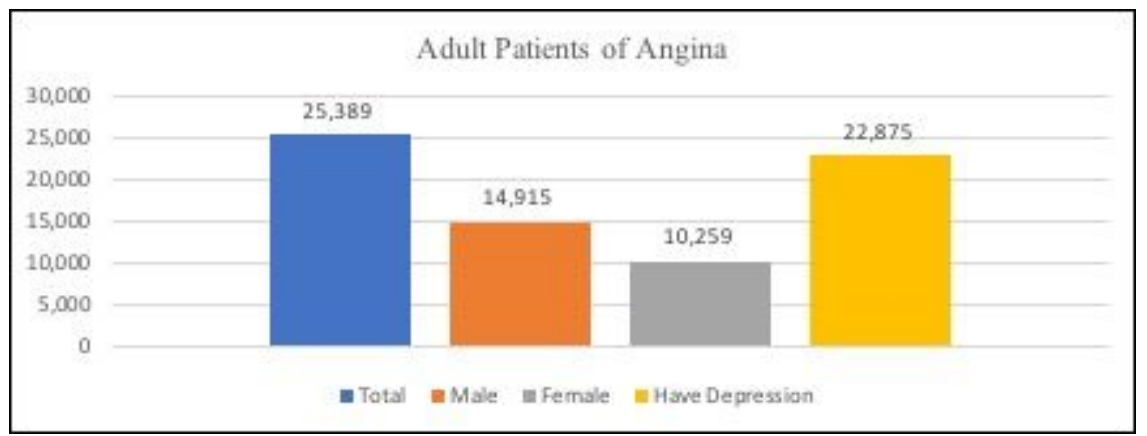

\section{Figure 1}

Distribution of adult patients with angina. 